\title{
Thomas Lewis (1881-1945) and cardiology in Europe
}

\author{
H A SNELLEN*
}

This year sees the centenary of the birth of one of the pioneers of cardiology: Thomas Lewis. I shall try to reflect on his place in the history of cardiology from a European point of view.

As far as personal contacts are concerned his ties with continental Europe were neither very tight nor extensive. His co-workers were usually British or from North America and other English speaking countries. Neither was Lewis a frequent traveller abroad. Moreover, Lewis was not easily approachable for those who did not know him well. The reports of his contemporaries, including his friends and collaborators, confirm the impression that I had myself on the one occasion that I visited him: very serious, concentrated in thought, quickly perceptive, and sometimes impatient with others who were slower in understanding; critical and of an independent mind. Those who knew him intimately were aware of other, warmer, traits in his character, as George Pickering testified in his "In memoriam". ${ }^{\dagger} \dagger$

For all his independence, Lewis had two older friends who were to a certain extent his guides for many years. One was James Mackenzie (1853-1925), the other Willem Einthoven (1860-1927). Lewis's first monograph on "The mechanism of the heart beat" (1911) was dedicated to both of them. There is no doubt, however, that Mackenzie was closer to Lewis and the more influential of the two.

Lewis was the son of a colliery owner and engineer in Wales. Educated at home by his mother and a private tutor, often roaming alone in the woods, interested in nature and in sport, but not in books of which his father had many, he must have been a rather lonely, enterprising boy. The experience of his youth had an influence on his later life, both in his work and in his devotion to bird photography during 'leisure. His decision to study medicine seems to have been stimulated by the example of two family physicians who were both clever conjurers. Admiring skill, as he continued to do in later life, Lewis believed that medical

^Present address: Van Brouchovenlaan 5, 2343 HC Oegstgeest, The Netherlands. †Apart from A Hollman's article in the "Dictionary of scientific biography", papers about Lewis are obituaries, including the informative paper of Pickering (1.c.). A complete biography with list of publications would be most welcome. studies would develop this quality. In fact, though I do not know about juggling, he certainly became an extraordinarily deft investigator. Having spent his first years of study in Cardiff he went to London and after qualification combined his clinical work in the London Chest Hospital with experimental analysis of his bedside experience in Starling's laboratory at University College. About that time his paper on the influence of respiration on venous and arterial tracings brought Lewis into contact with Mackenzie.

From the excellent biography on Mackenzie by Alex Mair, ${ }^{\star}$ and Pickering's description of Lewis (1.c.) it seems that there was a great similarity between Mackenzie and Lewis, not in appearance, nor in background or training; but Pickering thought that they had much in common and that much of what Lewis wrote in his obituary of Mackenzie might have been written of Lewis himself. Pickering also pointed out that Lewis followed Mackenzie in the choice of two main subjects of research: cardiac arrhythmias and pain, and, even, by strange irony, in falling victim to coronary artery disease. It may be true, as Mair suggests, that at times a love-hate relation was discernible between the two, but that is perhaps what one could expect from great congeniality and a strong influence (probably more than Lewis himself realised or cared to admit). The relation of Lewis to Einthoven was different: more distant and objective but with sincere mutual appreciation. Perhaps also more stable, as far as can be judged from the correspondence which was preserved by Einthoven and which is now kept in the Boerhaave Museum at Leiden.

Before quoting from this source, it may be useful to make some remarks about developments of cardiology in the 19th century before and at the time Lewis entered the scene. The following aspects will be dealt with briefly.

\section{(1) Valvular disease and endocarditis}

Important progress had been made in the 18th century in the study of signs and symptoms of patients in

\footnotetext{
״ "Sir fames Mackenzie MD 1853-1925 General practitioner" by Alex Mair, 1973.
} 
relation to subsequent necropsy findings. The foundation for the use of pathology as a frame of reference for diagnosis was thus laid when the new methods of percussion and auscultation were introduced. Auscultation led to a great interest in valve disorders, though Laënnec himself was more interested in pulmonary disease. Moreover, being acquainted with pathology but little with physiology he gave a wrong interpretation of the second heart sound, believing it to be the result of atrial contraction. Somewhat paradoxically, this greatly stimulated the research on normal and abnormal heart sounds. In due time valvular heart disease became a test of diagnostic acumen; perhaps it assumed greater importance, as the superiority of diagnostic over therapeutic achievements became painfully clear to members of the next generation, for instance Skoda. Bouillaud focused his attention not only on the valvular deformity, but on the process of endocarditis leading to it. He noticed the frequent association with acute rheumatism (as had H G Wells in 1810). Bouillaud described various types of endocarditis, differentiated according to the time course and to pathological findings. He noted also a widely divergent outcome and observed that the acute forms of endocarditis were often fatal, while the chronic course usually led to valvular deformity and impediment to the circulation.

At the middle of the 19th century, Virchow showed the relation between thrombus formation and emboli, and Pasteur prepared the ground for the discovery and recognition of bacteria, microscopally and on culture. In this way the recognition of the embolic and septic aspects of some forms of endocarditis became possible. In 1885 Osler divided endocarditis into simple and malignant; he suspected that the latter often, perhaps always, would be bacterial, but still allowed for a primary form without infection from outside. As bacteriology developed and blood cultures were used for diagnostic purposes, the difference between the acute and the protracted types of infective endocarditis was recognised; the acute type being part of a general septic disease, whereas the other was caused by ordinarily non-virulent cocci and nearly always grafted upon previously damaged valves. At the beginning of the 20th century the latter type received special attention; its relative frequency and virtually always fatal outcome after a prolonged course was established by studies like Osler's classic paper on chronic infective endocarditis in 1909 and those of Lenhartz and of Horder. Schottmüller identified the Streptococcus viridans and coined the name endocarditis lenta, which term Libman replaced by subacute bacterial endocarditis. Lewis showed with Grant that the existence of bicuspid aortic valves, which turned out to be common, could offer the opportunity for this type of endocarditis to develop.

Lewis also took a very distinct stand against the generally overrated prognostic importance of valvular defects, and indeed of all heart murmurs, many of which were not indicative of valvular involvement at all. In a similar way to Mackenzie, he considered the condition of the heart muscle the most important factor in most cases of valvular disease and stressed that only the test of bodily exercise could show whether or not the function of the heart was impaired. His influence doubtless contributed to reducing the predominant place of valvular defects in cardiology.

A second factor in the decline of interest in valvular disease and auscultation (even in France, but to a lesser degree than elsewhere) was the attention given to hypertension and arteriosclerosis, that is until the advent of cardiac surgery.

\section{(2) Hypertension and arteriosclerosis}

Although the brilliant research of Stephen Hales in dogs and horses had clearly proved the variability and self-regulating character of blood pressure, its clinical implications were not understood until more than a hundred years later, that is in the second half of the 19 th century.

In part this was because of the slow development of the technique of measuring blood pressure in man, which went through the stages of recording the arterial pulse by the sphygmograph of Vierordt and the improved instrument of Marey to the various types of sphygmomanometers, of which that of von Basch was the first to come into clinical use for measuring blood pressure. In about 1900 Riva Rocci's and von Recklinghausen's armcuffs, and especially the invention of the auscultatory method by Korotkoff, brought the simplification which was necessary for general use. This technical progress, however, depended on and was closely interwoven with the development of two concepts, namely of blood pressure as a basic factor in haemodynamics, and of hypertension as a morbid sign both as part of Bright's disease and in its own right; these two notions took almost a century to develop and be accepted.

At the same time the difficult problem of arteriosclerosis and its relation to hypertension on the one hand and to specific local sequelae, particularly in the myocardium, on the other was studied and at least partly clarified. Whereas hypertension was first ascribed to renal and later to generalised arteriosclerosis, further experience made it clear that the relation was the other way round. Myocardial fibrosis and fatty degeneration had been studied extensively and were usually considered to be theoutcome of myocarditis or of intoxication, chemical or bacterial, but late in the 19th century experimental and pathological evidence accumulated showing their dependence on coronary insufficiency. The faded interest in angina pectoris also revived and its relation to coronary arteriosclerosis 
(established by Jenner a century earlier) was again pointed out. Nevertheless, the coronary origin of angina pectoris was far from being generally accepted in the first decades of Lewis's career. Though Herrick delineated in 1912 and in 1919 the clinical feature of coronary thrombosis (that is, cardiac infarction), confirmed the relation with angina pectoris, and clarified the pathology, the cause of angina pectoris was still often considered uncertain in the 1920's. Prominent cardiologists like Clifford Allbutt, Wenckebach, and Vaquez preferred to assume an aortic origin.

Lewis's contribution was made somewhat later and was of a different order. His views gained much attention in Europe by placing angina pectoris in a wider context of arterial obstruction, in particular by stressing the similarity to intermittent claudication and suggesting the production of a $\mathrm{P}(\mathrm{ain})$ factor by ischaemia of a working muscle.

\section{(3) Recording methods}

Finally in this brief and summary review of developments in the 19th century, many of which bore fruit only later, mention should be made of physiology, which had been overshadowed by pathology, and which was virtually reborn in the first half of the 19th century and soon began to thrive. Its main contribution to cardiology was the introduction of recording instead of visual observation or indirect demonstration (for example, detection of cardiac electrical impulses by a nerve-muscle preparation). Marey with Chauveau, modifying Ludwig's kymograph, recorded intracardiac and aortic pressure in the horse through heart catheterisation. At the same time external pulsations from veins, arteries, and the heart itself were recorded by means of Marey's sphygmograph. Apart from the use of these tracings for the study of cardiodynamics, as they were intended, they proved also of great value for research on cardiac arrhythmias, which was almost simultaneously undertaken by two country doctors who combined dexterity with careful analysis and keen perception, to derive important results from a simple method. These two were of course Mackenzie and Wenckebach, and though their subsequent roads to fame were different, they had an affinity and were good friends as appears from Mair's quotations from their correspondence before the first world war. Wenckebach's contact with Lewis was much more limited, as it was with Einthoven.

In the meantime Marey had been making photographic records of various movements, which ultimately resulted in the development of cinematography. For cardiology it was of particular interest that he made photographic records of the mercury column of Lippmann's electrometer. He studied in this way the potential variations of the exposed heart of the frog and the tortoise, and it was with this same method. that Waller showed how cardiac electrical activity can be detected at the body surface of animals and also of man.

As a young professor of physiology (appointed while he was still a student) Einthoven turned to electrophysiology, especially of the heart: Before he did so, he showed by vastly improving the Lippmann instrument and its recording system, his physical and technical talents; in addition, his urge to perfection and his untiring attention to detail were apparent; in short, to quote Wiggers: "his genius-a human trait, that Carlisle has defined as the ability to take infinite pains." Einthoven then proceeded to record phonocardiograms for the first time (in 1894). While taking electrocardiograms, he corrected them for the sluggishness of the electrometer mathematically. Finally he designed his own instrument, the requirements for which he calculated from a study of the mirror galvanometer of Deprez-d'Arsonval, a much less sensitive instrument but with greater speed of deflection.

The first tracings from the new galvanometer were published in 1903 and the next 10 years were spent on improving and standardising all details of construction, as well as recording and collecting a large series of electrocardiograms from experiments, and from normal subjects and patients. To the latter end Einthoven constructed special telephone cables connecting his laboratory to the hospital, a mile away. Many forms of arrhythmia were discovered, some of them not yet understood; the signs of atrial and ventricular hypertrophy and of heart block were recognised and the mutual relation of the extremity leads was made clear (1906 and 1908). At this point Lewis also acquired his electrocardiograph.

Einthoven took major steps towards understanding the electrocardiogram in 1912 and in 1913, when he published his simplified scheme of the human body as an equilateral triangle with a vector (electrical axis) in its centre as the summation of the intracardiac potentials, varying from instant to instant in length and direction. The relation of the extremity leads to each other as projections of the same vector on the three sides of the triangle, and the changes of the QRS complex in lead III with respiration and shifting of body position could be clarified in this way and the foundations for vector electrocardiography were laid. Lewis used the calculations of the vector's angle of inclination (angle $\alpha$ of the electrical axis) to study the spread of the excitation wave in the heart, as well as measuring experimentally the times of arrival of the excitation wave at various points on the epicardial and endocardial surface. There was much correspondence between Einthoven and Lewis about the angle $\alpha$ as well as about such technical and physical details as body resistance, polarisation in the skin, phonocardiographic apparatus, etc.

To give a few examples: on 6 November 1913 Lewis 
wrote, "I did not feel at all satisfied with the calculations which I sent. It was for this reason that I sent them, because I know that you would tell me candidly if they were not correct. . . . Could you give me any indication of the direction in which I have gone wrong, and I will read your paper again from this point of view ..." An extensive letter from Einthoven followed, after which Lewis replied (13 November 1913), "I am much obliged to you for your letter explaining my error in calculation. It is very obvious to me now that you have explained it ..."When in 1915, however, Lewis wrote to inquire why Einthoven had chosen the equilateral triangle for his schematic approach, the answer was apparently less clear to him; on 20 February 1913 Lewis wrote: "I have to thank you for your letter in regard to the electrical axis. I fear that I have insufficient knowledge of trigonometry, fully to appreciate your explanation; so I propose relying upon your conclusion that the equilateral triangle is the most satisfactory." The preceding correspondence has been published. ${ }^{2}$

On his side, Einthoven mostly answered questions and patiently corrected errots from the physical point of view. At the same time he showed his admiration for many of Lewis's experiments. He rarely criticised them unless physical principles or definitions of classification and nomenclature were involved. This was especially apparent when the contact was resumed after the war and Einthoven received in 1918 Lewis's important series of papers on the spread of the excitatory process in the vertebrate heart. Einthoven acknowledged the receipt with warm praise, particularly for the exact timing of the excitation and the differentiation between intrinsic and extrinsic effects (that is, locally originating and transmitted potential differences).

To show his interest, Einthoven added a long list of carefully worded criticisms. To this Lewis replied ( 9 December 1918): . . . "I not only appreciate the kindly way in which you speak of the paper, but appreciate and value equally your criticisms. Criticism of such a kind is most helpful always; that, I well know, is why you send it to me...".

This series of investigations was virtually the last which Lewis carried out in the field of electrocardiography. During the second half of the first world war he had already started some investigations on the vascular reactions of the skin, the subject on which he was to concentrate fully in the 1920's. Much of his work during the first world war was devoted to the study of cardiac symptoms in soldiers, most of which, as Da Costa had found already in the American Civil War, were not the result of heart disease. Lewis was not convinced, however, that the complaints were entirely psychogenic. He suggested as possible causes the general condition of the men (for example, infections) and lack of training, faulty recruitment, etc. There were no spectacular results, not even in the subsequent examination five years later by Grant, who also examined the cases of valvular disease after 10 years; but the influence of this plain demonstration of the difference between cardiac symptoms and cardiac disease was undeniable throughout Europe. The repercussion of the well-organised control examinations in order to establish prognosis was less perceptible, though in retrospect equally important. Effort syndrome remained a familiar notion for many doctors. I am afraid, however, that during the second world war some of us in occupied Europe misused the term deliberately in order to raise vague anxiety symptoms to the rank of a serious diagnosis, by which we intended to free many men from recruitment for work in Germany.

The last publications of Lewis on cardiological research were: his Mellon lecture of 1922, the third, much enlarged, edition of the "Mechanism and graphic registration of the heart beat" (1925), and the textbooks for students on "Disease of the heart" (1933), "Vascular disorders of the limbs" (1936), and new editions of his "Clinical disorders of the heart beat" (I have the 6th edition of 1925) and finally the "Exercises in human physiology" (1946) which stands apart both by its content and its unfortunate time of appearance, at least from a European point of view, as it passed relatively unnoticed amid a wealth of new information.

The other didactic books exerted widespread influence, particularly in such simple but important issues such as the estimation of venous pressure from the filling of the veins and the analogy of angina pectoris to intermittent claudication. "The mechanism of the heart beat" was of more fundamental importance but reached a smaller audience. The Mellon lecture, ${ }^{\star}$ finally, contained new conclusions from earlier research and considered cardiac excitation as a sequence of electrical events originating in small units rather than in the cardiac muscle as a whole. Lewis had discussed this point with Einthoven, who suggested that the microscopical myocardial segments (the term "cell" was not yet used because the heart muscle was supposed to be a syncytium) would be the place of origin of the "limited potential differences" as Lewis called them.

This view was briefly published by Einthoven in 1921 and mentioned by Lewis in his "Mechanism of the heart beat" (1925). Though neither of them undertook any further research on the subject, this concept appears to herald later developments in cellular electrophysiology.

As a last quotation from the correspondence of Lewis and Einthoven, I insert a few lines from Lewis's letter of congratulation to Einthoven in October 1924: "The splendid news of your Nobel Prize came this morning and gave me very great pleasure. You have given so much to Physiology and Medicine that the prize in itself is but a small return, but I rejoice and there will be

${ }^{\star}$ Arch Intern Med 1922; 30: 269. 
many rejoicing with me, that your great work has received this public recognition . . ." Einthoven thanked Lewis somewhat later (24 January 1925), inviting him to stay in his home for the planned joint meeting of the British and Dutch physiological societies. I quote: ". . . Your words have touched me deeply. I owe so much to you. Without your steady and excellent work to which you have devoted a great part of your life there would have been in all probability no question of a Nobel Prize for me ...". This last remark was again made by Einthoven in his acceptance speech at Stockholm.

I shall not discuss the investigations of Lewis in his last period, collected in "The blood vessels of the human skin and their responses" (1927) and in "Pain" (1942), which have little connection with cardiology.

It is intriguing to guess, however, why Lewis abruptly ended his successful career in cardiology. His co-workers have offered two suggestions in this respect, based on direct information: one is, that the main opportunities in electrocardiographic research were exhausted ("the cream was off"), the other, that he had grown weary of being tied to an instrument. The first judgement was soon belied by experience (for example, electrocardiographic studies in coronary disease); the second would perhaps be easier to understand if there should be a relation to a third factor, namely a return to Mackenzie's sphere of influence by simplifying scientific research and concentrating on man. Lewis may have chosen, moreover, to follow the path which he had described in Mackenzie's obituary as, "an eager search for some fundamental law or laws which, like the law of Dalton in the sphere of chemistry, shall illuminate the science of Physiology and Medicine. . . . $\mathrm{He}$ (that is Mackenzie) clearly perceived how, dangerously, innumerable and ill-assorted facts are crowded together, their meaning confused, by an ever increasing haste and how little, to this tangle of recorded observations is applied the simplifying, clarifying help of a broad inductive reasoning. ..."

In any case, I can hardly accept as coincidence that Lewis, just like Mackenzie in his "Future of medicine", felt impelled to record his own experience and his expectations for the future in his book on "Clinical science" (1934) and in his "Harveian oration" (1933) collected together with his Huxley Lecture on "Clinical sciences within the university" and other addresses in "Research on medicine". The impact of these views may have been greater in Britain than on the continent, but their basic importance was widely recognised. On the other hand, in retrospect, it is not difficult to see that the simplified research with its orientation towards man, inevitably led to many more complicated biochemical, immunological, and neurophysiological problems than Lewis appears to have expected.

I would like to thank the Boerhaave Museum, Leiden, for access to unpublished correspondence between Lewis and Einthoven.

\section{References}

1 Pickering GW. In memoriam. Clin Sci 1947-48; 6: 3-11.

2 Snellen HA. Selected papers on electrocardiography of Willem Einthoven. The Hague: Leiden University Press, 1977: 243-6.

Requests for reprints to Professor H A Snellen, Van Brouchovenlaan 5, 2343 HC Oegstgeest, The Netherlands. 